\title{
Significance of Outdoor Time for Myopia Prevention: A Systematic Review and Meta-Analysis Based on Randomized Controlled Trials
}

\author{
Kai Cao ${ }^{a}$ Yue Wan ${ }^{b}$ Mayinuer Yusufu ${ }^{a} \quad$ Ningli Wang ${ }^{a}$ \\ a Beijing Institute of Ophthalmology, Beijing Tongren Eye Center, Beijing Tongren Hospital, Capital Medical University, \\ Beijing, China; ${ }^{\mathrm{b}}$ Beijing Tongren Eye Center, Beijing Tongren Hospital, Capital Medical University, Beijing Ophthalmology \\ and Visual Sciences Key Laboratory, Beijing, China
}

\section{Keywords}

Outdoor time $\cdot$ Outdoor activity $\cdot$ Myopia $\cdot$ Randomized controlled study $\cdot$ Meta

\begin{abstract}
Background: Myopia, especially high myopia, would cause damage in the choroid, retina and sclera, thereby leading to vision loss. Although refractive error correction can help improve visual acuity, the pathology of myopia, a global issue, remains unclear and myopia progression, as well as concomitant fundus progression, remains uncontrolled. Under such circumstances, prevention of myopia is of great significance and thus should be prioritized. Objective: To explore whether outdoor time has positive significance for myopia prevention. Search Methods: Databases of Pubmed, Science Direct, the Cochrane Library, the Chinese National Knowledge Infrastructure and the Wanfang Database were searched. The following terms or their combinations were used: myopia, prevention, control, random, randomized, randomization, intervention, outdoor. The full search strategy was shown in the Appendix below. The databases were last searched on October 24, 2018. Selection Criteria: Randomized controlled trials (RCTs) that participants accepted outdoor activity as an intervention measure for myopia prevention were included.
\end{abstract}

Data Collection and Analysis: Two review authors independently extracted data and assessed the risk of bias for included studies. A fixed-effects model was applied, given that the heterogeneity among included studies was small. Main Results: Five RCTs with 3,014 subjects were included. Subjects' age ranged from 6 to 12 years, and the follow-up duration ranged from 9 to 36 months. Spherical equivalent error (SER) of the outdoor group was larger than that of the control group, and the pooled mean difference (MD) was 0.15 (95\% $\mathrm{Cl}$ 0.06-0.23) diopter (D). The change in SER of the outdoor group was smaller than that of the control group, with a pooled MD of 0.17 (95\% Cl 0.16-0.18) D. New myopia cases in the outdoor group were fewer than that of the control group, and the pooled risk ratio was 0.76 (95\% $\mathrm{Cl} 0.67-0.87$ ). The change in axial length of the outdoor group was smaller than that of the control group, and the pooled MD was -0.03 $(95 \% \mathrm{Cl}-0.03$ to -0.03$) \mathrm{mm}$. For all analyzed outcomes, there was no heterogeneity across included studies $\left(I^{2}=0 \%\right)$ and there was no publication bias either. Conclusion: Outdoor time helps slow down the change of axial length and reduce the risk of myopia.

(c) 2019 S. Karger AG, Basel

\section{KARGER}

(c) 2019 S. Karger AG, Basel

E-Mail karger@karger.com

www.karger.com/ore
Ningli Wang

Beijing Institute of Ophthalmology, Beijing Tongren Eye Center Beijing Tongren Hospital, Capital Medical University

No. 17, Hougou Alley, Dongcheng District, Beijing 100005 (China)

E-Mail wningli@vip.163.com 


\section{Introduction}

\section{Description of the Condition}

Myopia, which is usually defined as the spherical equivalent error (SER) of below $-0.5 \mathrm{D}$, refers to a condition where a person can see only objects that are near, as the image of distant objects could not be focused appropriately on the retina. Myopic eyes usually have longer axial length compared to normal eyes.

\section{Epidemiology}

Myopia is a global public health issue, and it is estimated that $28.5 \%$ of men and $27.3 \%$ of women worldwide are short-sighted [1]. In Asia, the situation is even severer; China alone has a myopic population of $>0.4$ billion, and the prevalence of myopia in teenagers is up to $90 \%$ [2].

\section{Etiology and Risk Factors}

Many factors are potential causes of myopia and myopia progression, including near work [3], shortage of outdoor time [4], Asian ethnicity [5], high educational level, parental myopia, low serum Vitamin D [6], development of parapapillary atrophy [7], and even allergic inflammation [8].

\section{Importance of Outdoor Time}

Compared to ethnicity, education, heredity and other factors, outdoor time, which could be modified by encouraging outdoor activity, is a more promising intervention method, and thus many researchers are devoted to identifying whether outdoor time helps control myopia.

\section{Current Researches on Outdoor Time for Myopia Prevention}

However, evidence from different studies is contradictive. In Singapore, Low W [9] conducted a cross-sectional study including 3,009 of 0.5-6-year-old Chinese children and compared the outdoor time between myopic children and non-myopic children, for which, no statistical difference was found. In another 2 cross-sectional studies, Lu et al. [10] and Ip et al. [11] reported similar findings. In another study in Singapore carried out by Saw et al. [12], 994 of 7-9-year-old children were followed for 3 years in the cohort study, and no association was found between outdoor time and myopia. A similar finding was reported by Li et al. [13] and Chua et al. [14] in another 2 cohort studies.

On the contrary, in a cross-sectional study including 1,344 youth of 19-22 years old, McKnight et al. [15] reported an inverse relationship between SER and ocular sun exposure, which was measured by conjunctival ultra- violet autofluorescence. Deng et al. [16] reported that myopes spent significantly fewer hours $(8.25 \pm 6.25 \mathrm{~h} /$ week) than non-myopes (10.95 $\pm 5.95 \mathrm{~h} /$ week) in sports/ outdoor activity during the school year. Khader et al. [17], Mutti et al. [18], Saxena et al. [19], Sun et al. [20], Guo et al. [21], Lin et al. [3] and Hsu et al. [22] and Read et al. [23] also reported the positive effect of outdoor time on myopia control. In a randomized comparative study, Jin et al. [24] revealed that an additional 20 minutes recess outside classroom could help slow down the change speed of refractive error. He et al. [25] carried out a randomized controlled trial (RCT) in China, in which an addition 40 min of school outdoor activity was added in the outdoor group. Over a 3-year follow-up, the change of both refractive error and axial length were slower than that of control group. Wu et al. [26] reported a similar finding in another RCT conducted in Taiwan.

There was even a study revealing outdoor time as a risk factor for myopia: Czepita et al. [27] reported that with the increase of outdoor activity time, students' SER significantly increased.

\section{Significance of this Systematic Review and Meta-Analysis}

Whether outdoor time helps control myopia remains controversial. In this review, we aim to provide an updated evaluation on the effect of outdoor time on myopia control. The refractive error, change of refractive error, change of axial length, and number of new myopia cases between the outdoor group and the control group would be compared.

\section{Methods}

Inclusion and Exclusion Criteria

Types of studies. This review included only RCTs.

Types of participants. We included trials in which participants accepted outdoor activity as an intervention method to increase outdoor time for myopia prevention. Randomization of participants at an individual level or a school cluster level was both acceptable.

Types of interventions. As this review only focuses on the effect of outdoor time on myopia prevention, only trials using outdoor activity as an intervention method were included.

\section{Types of Outcomes Measures}

Primary outcomes. The primary outcome for this review was refractive error (SER) that measured at the year of last follow-up.

It is worth mentioning that in $\mathrm{He}$ et al. [25] research, cycloplegic refraction was performed only on those children who had parental consent, and the percentage of cycloplegic refraction in the outdoor group and the control group was 94.55 and $79.65 \%$ respectively. In other studies, all subjects were measured with cycloplegia.
Cao/Wan/Yusufu/Wang 


\section{Secondary Outcomes}

1. Mean change in SER

2. Number of new myopia cases:

Subjects whose SER was above $-0.5 \mathrm{D}$ at baseline and was below $-0.5 \mathrm{D}$ at the last follow-up year was defined as new myopia cases. Number of new myopia cases in both intervention group and control group was extracted and then compared.

3. Change of axial length

The change of axial length between intervention group and control group was compared. Three studies measured axial length, with 1 using a noncontact ocular biometry system (Lenstar LS 900) and another 2 using the IOL Master (Carl Zeiss Meditec).

Search Methods for Identification of Studies

Databases of Pubmed, Science Direct, the Cochrane Library, the Chinese National Knowledge Infrastructure and the Wanfang Database were searched. The following terms or their combinations were used: myopia, prevention, control, random, randomized, randomization, intervention, outdoor. The full search strategy is shown in the Appendix part below. The electronic databases were last searched on October 24, 2018.

See: Appendices for details of search strategies for Pubmed (Appendix 1) and other databases (Appendix 2)

\section{Data Collection and Analysis}

Selection of studies. Two review authors, 1 clinician (N.W.) and 1 methodologist (K.C.), assessed the titles and abstracts of all papers independently in the initial screening process. If there were different opinions on whether a paper should be included or excluded, the full article would be assessed and discussed.

\section{Data Extraction and Management}

Two reviewers extracted the data for the primary and secondary outcomes according to data collection forms designed by the authors' team. Data measured at the last follow-up year were collected. For continuous data, including SER, change of SER and AL, the mean values and SDs were extracted. For categorical data, such as new myopia cases, the number of each group was extracted. One reviewer entered the data into $\mathrm{R}$ software and another reviewer performed verification.

\section{Assessment of Risk of Bias in Included Studies}

The risk of bias tool recommended by the Cochrane Collaboration [28] was applied to assess risk of bias of each study from the following 6 aspects: sequence generation, allocation concealment, blinding of participants and personnel, blinding of outcome assessors, incomplete outcome data, selective outcome reporting. The risk of bias for each aspect is graded as "low," "unclear," or "high." For example, if a study generated randomization sequence in an appropriate way like using SAS software or using random number table, the risk of bias on sequence generation for this study is considered.

\section{Measures of Treatment Effect}

Mean differences (MDs) were reported for continuous outcome measures, and risk ratios (RRs) for dichotomous outcomes.

\section{Unit of Analysis Issues}

In this review, the unit of analysis was "person" instead of "eye," for example, if both eyes of a participant met the criteria of myopia at the last follow-up year, the participant would be treated as "one" new myopia case.

Assessing the Effect of Outdoor Time on

Myopia Prevention
Dealing with Missing Data

The studies were analyzed based on available information.

Assessment of Heterogeneity

Before estimating the pooled effect, the heterogeneity across studies was assessed first by Q test and $I^{2}$ statistic. $I^{2}$ describes the percentage of variability in effect estimates that is due to heterogeneity rather than to chance. If the $p$ value was below 0.05 or the $I^{2}$ was above $50 \%$, the heterogeneity among included studies would be considered large.

Assessment of Reporting Biases

If there was any outcome assessed but not reported, a reporting bias would be considered present.

\section{Data Synthesis and Statistical Analysis}

MD with 95\% CI was applied to estimate continuous outcomes, and RR with $95 \%$ CI was extracted to estimate categorical outcomes. All the analysis was performed with open source R program (version 3.4.4). If the $I^{2}$ was below 50\%, a fixed-effects model would be applied to calculate the pooled effect size [29]. Egger's test was used to check publication bias [30]. The significance level was 0.05 , two-tailed.

\section{Subgroup Analysis and Sensitivity Analysis}

In this review, no subgroup analysis or sensitivity analysis was performed as the heterogeneity of included studies was small.

\section{Results}

\section{Description of Studies}

Results of the search. An electronic literature search was performed and 268 records of journal articles were identified. After duplicates were removed, there were 232 left. After screening the titles and abstracts, full-text copies of 43 records for further review were obtained. Of those, 32 full articles were excluded due to ineligible study design, inadequate inclusion criteria of subjects or uninterested interventions. Six full-text articles were excluded due to insufficient data of outcomes. Five RCTs [24-26, $31,32]$ met the inclusion criteria, and the paper selection process was shown in Figure 1.

Included studies. Among the included 5 studies, subjects' age ranged from 6 to 12 years (Table 1), and the follow-up duration ranged from 9 to 36 months. One study performed randomization at individual level, while other studies performed school-cluster randomization.

All included studies used outdoor activity as an intervention method, but with varied length of outdoor time. Two studies added a 40-min recess for children in school days, 1 study added a 2-3 h outdoor activity for children on weekend, 1 study encouraged participants to have outdoor time of $11 \mathrm{~h}$ or more every 7 days, and 1 study let children do outdoor activity $>14-15$ h per week.

Ophthalmic Res 2020;63:97-105 
Fig. 1. Flowchart of paper selection.

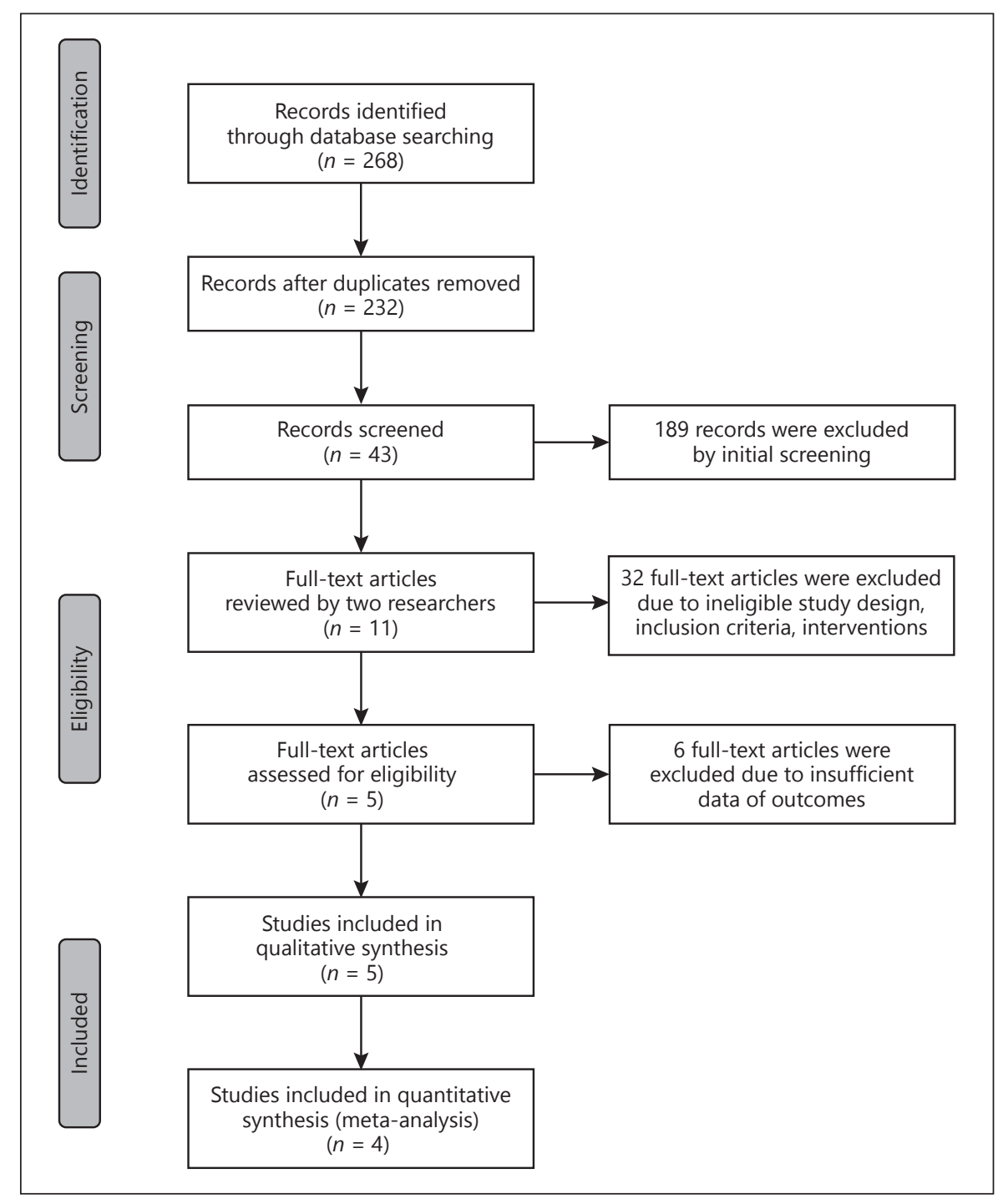

\section{Assessment of Risk of Bias}

Analysis of risk of bias was shown in Figure 2. All included studies generated a random sequence in an appropriate way, and thus there was a low risk of bias on random sequence generation for all included studies. For allocation concealment, Ngo et al. [32] stated clearly that envelopes were used, and therefore, the risk of bias was low; however, other studies performed a cluster randomization, which means allocation concealment was unfeasible, and so the risk of bias was high. As for the blinding method, incomplete data and selective reporting, the risk for most studies was unclear, but He et al. [25] stated clearly that blinding method was not applied, and hence, the risk of bias was high. Jin et al. [24] randomly selected a quite small group out of all subjects for outcome assessment; thus, the risk of bias on incomplete data was high.

\section{Effects of Interventions (Comparison of Outcomes} between the Outdoor Group and the Control Group) Refractive error after intervention. Three studies included in this review made comparison on SER measured at the last follow-up year between the outdoor group and the control group, and in every single study, the SER of the outdoor group was found to be better (the absolute value was smaller) than that of the control group. The pooled MD, as shown in Figure 3, was 0.15 (95\% CI 0.06$0.23) \mathrm{D}$, meaning that SER of the outdoor group was better than that of the control group, and there was no heterogeneity across included studies $\left(I^{2}=0 \%\right)$.

Change in refractive error. Four studies reported the SER change after intervention. The forest plot of SER change was shown in Figure 4. Pooled MD between the outdoor group and the control group was 0.17 (95\% CI 
Fig. 2. Analysis of risk of bias (ROB).

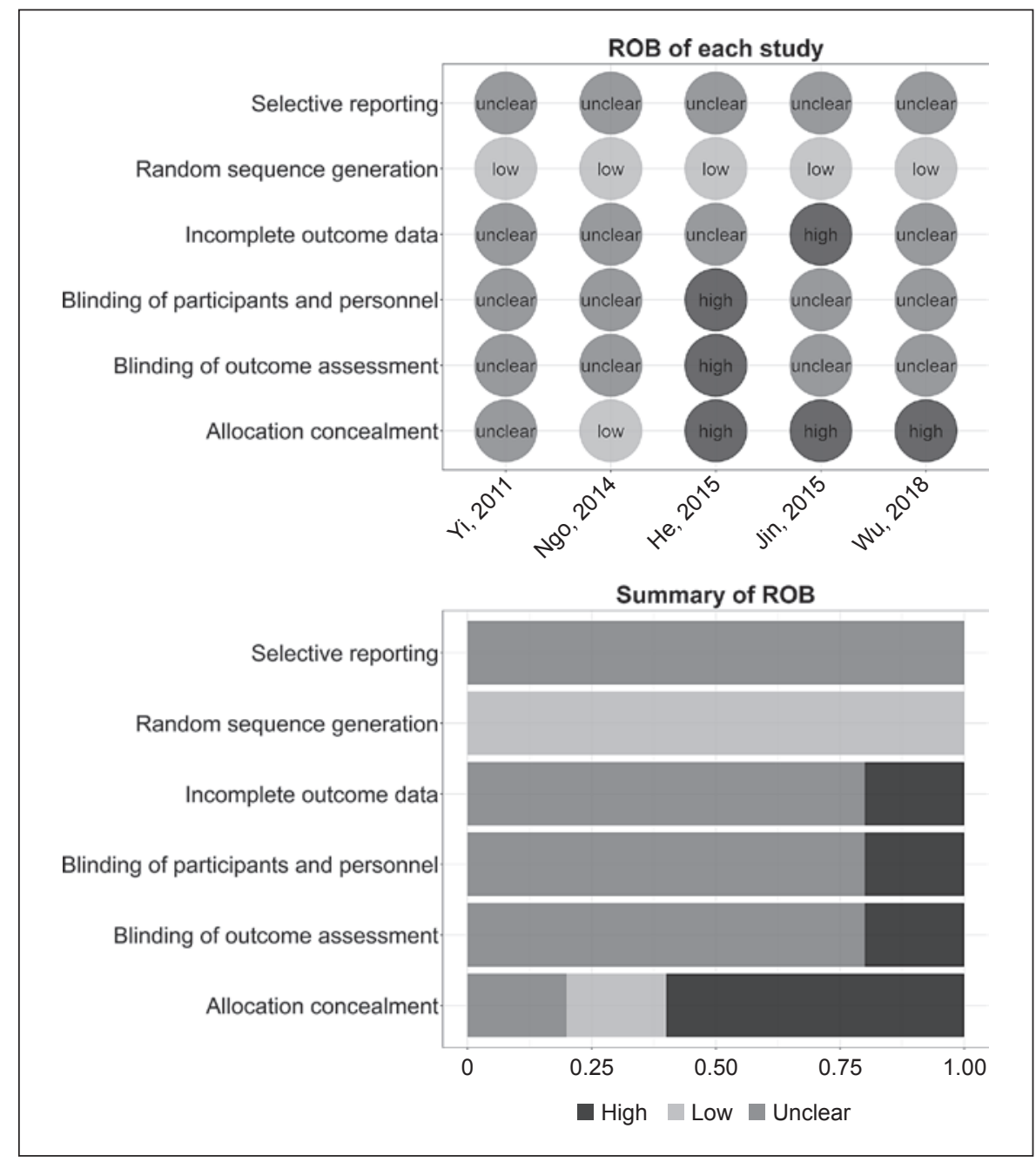

Table 1. Characteristics of included studies

\begin{tabular}{|c|c|c|c|c|c|c|c|c|}
\hline \multirow[t]{2}{*}{ Author } & \multirow[t]{2}{*}{ Year } & \multirow[t]{2}{*}{ Area } & \multirow[t]{2}{*}{ Randomization } & \multirow{2}{*}{$\frac{\text { Subjects' age, years }}{\text { intervention control }}$} & \multicolumn{2}{|l|}{ Sample size } & \multirow{2}{*}{$\begin{array}{l}\text { Follow, } \\
\text { months }\end{array}$} & \multirow[t]{2}{*}{ Intervention measure } \\
\hline & & & & & intervention & control & & \\
\hline $\begin{array}{l}\text { Yi } \\
\text { et al. [31] }\end{array}$ & 2011 & China & Individual level & $7-11$ & 37 & 29 & 24 & $\begin{array}{l}\text { Let children do outdoor activity more than } 14-15 \mathrm{~h} \\
\text { per week }\end{array}$ \\
\hline $\begin{array}{l}\text { Ngo } \\
\text { et al. [32] }\end{array}$ & 2014 & Singapore & Cluster level & $6-12$ & 147 & 138 & 9 & $\begin{array}{l}\text { The families were encouraged to attend } 2-3 \mathrm{~h} \\
\text { outdoor hikes/sports/activities organized in } \\
\text { conjunction with National Parks and Nature Society } \\
\text { guides on weekends at least twice per month }\end{array}$ \\
\hline $\begin{array}{l}\mathrm{He} \\
\text { et al. [25] }\end{array}$ & 2015 & China & Cluster level & $6.6 \pm 0.34$ & 853 & 726 & 36 & $\begin{array}{l}\text { An additional } 40 \text {-min outdoor activity class in schoo } \\
\text { days; and a promoted outdoor activity by providing } \\
\text { school bags, umbrellas, water bottles, and hats with } \\
\text { outdoor activity logos in weekends }\end{array}$ \\
\hline $\begin{array}{l}\text { Jin } \\
\text { et al. [24] }\end{array}$ & 2015 & China & Cluster level & $10.77 \pm 2.14 \quad 10.42 \pm 2.72$ & 214 & 177 & 12 & $\begin{array}{l}2 \text { additional recess programs of } 20 \mathrm{~min} \text { in school } \\
\text { days }\end{array}$ \\
\hline $\begin{array}{l}\text { Wu } \\
\text { et al. [26] }\end{array}$ & 2018 & China & Cluster level & $6.34 \pm 0.48$ & 267 & 426 & 12 & $\begin{array}{l}\text { Participants were encouraged to have } 11 \mathrm{~h} \text { or more } \\
\text { of outdoor time every } 7 \text { days }\end{array}$ \\
\hline
\end{tabular}




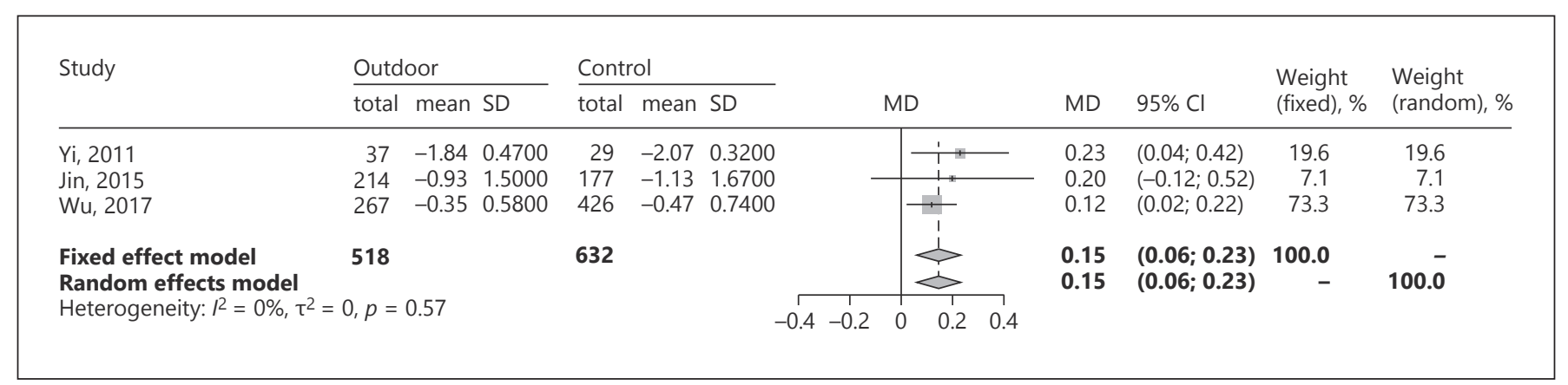

Fig. 3. Forest plot of comparison of SER at last follow-up between outdoor group and control group. MD, mean difference.

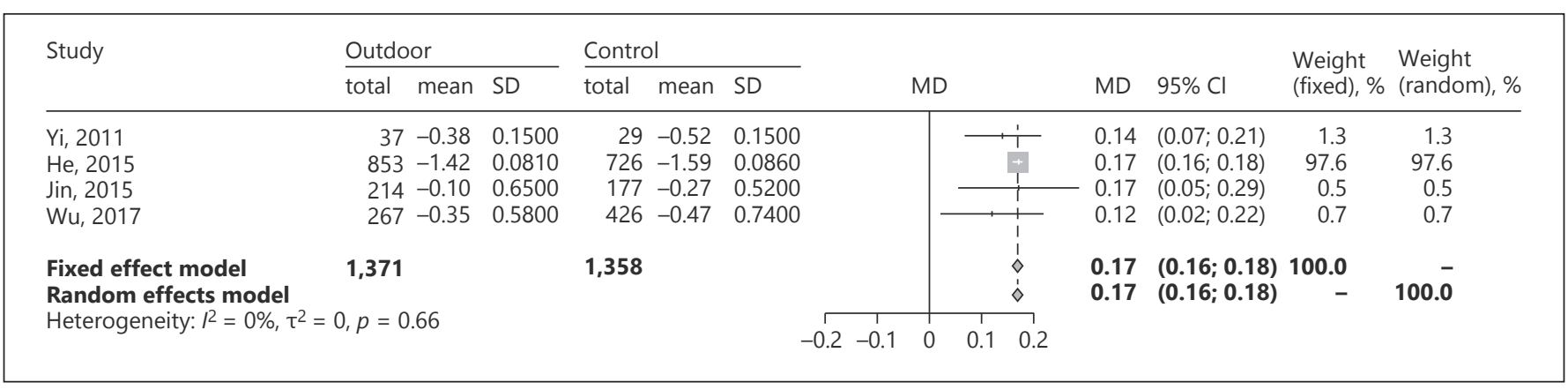

Fig. 4. Forest plot of comparison of diopter growth between the outdoor group and control group. MD, mean difference.

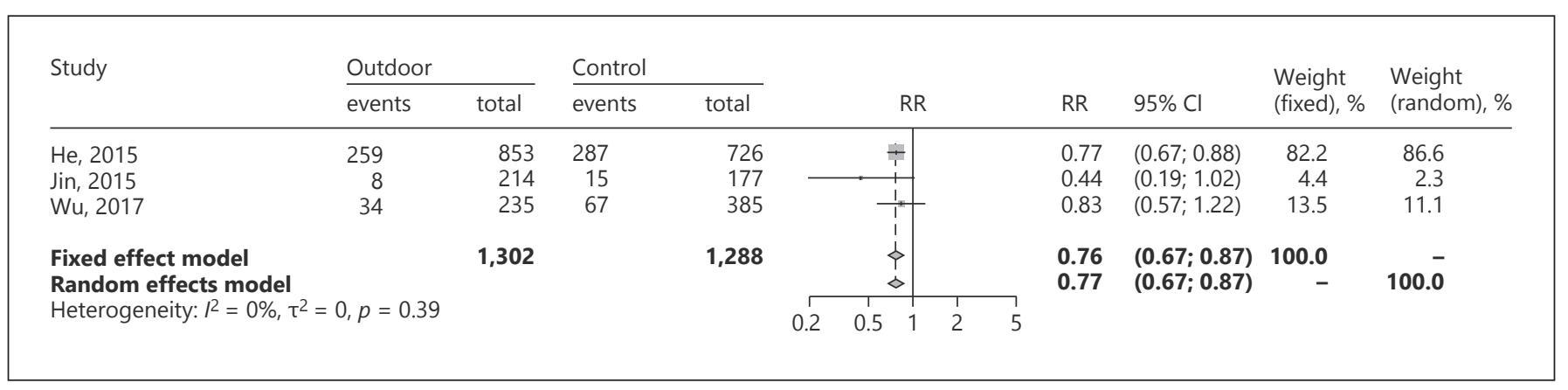

Fig. 5. Forest plot of comparison of new myopia cases between outdoor group and control group. MD, mean difference.

0.16-0.18) D, indicating that the SER change of the outdoor group was slower than that of the control group. The $I^{2}$ was $0 \%$, indicating that there was no heterogeneity among included studies.

Number of new myopia cases. The risk of developing myopia was assessed for both groups. As shown in Figure 5, there were fewer new myopia cases in the outdoor group, and the pooled RR was 0.76 (95\% CI 0.67$0.87)$. Children in the control group were faced with a higher risk of developing myopia. The $I^{2}$ was $0 \%$, indicating that there was no heterogeneity across included studies.

Change in axial length. As shown in Figure 6, the change of axial length in the outdoor group was statistically smaller than that of the control group, and the pooled MD was -0.03 ( $95 \% \mathrm{CI}-0.03$ to -0.03 ) $\mathrm{mm}$, there was no heterogeneity among included studies either $\left(I^{2}=\right.$ $0 \%)$. 


\begin{tabular}{|c|c|c|c|c|c|c|c|c|c|c|c|c|c|}
\hline \multirow{3}{*}{$\begin{array}{l}\text { Study } \\
\mathrm{He}, 2015\end{array}$} & \multicolumn{3}{|c|}{ Outdoor } & \multicolumn{3}{|c|}{ Control } & \multirow{2}{*}{\multicolumn{3}{|c|}{$\mathrm{MD}$}} & \multirow[b]{2}{*}{ MD } & \multirow[b]{2}{*}{$95 \% \mathrm{Cl}$} & \multirow{2}{*}{\multicolumn{2}{|c|}{$\begin{array}{l}\text { Weight Weight } \\
\text { (fixed), \% (random), \% }\end{array}$}} \\
\hline & \multirow{2}{*}{$\begin{array}{r}\text { total } \\
853\end{array}$} & \multirow{2}{*}{$\frac{\text { mean }}{0.95}$} & \multirow{2}{*}{$\begin{array}{l}\text { SD } \\
0.0200\end{array}$} & \multirow{2}{*}{$\begin{array}{r}\text { total } \\
726\end{array}$} & \multirow{2}{*}{$\begin{array}{l}\text { mean } \\
0.98\end{array}$} & SD & & & & & & & \\
\hline & & & & & & 0.0250 & † & & & -0.03 & $(-0.03 ;-0.03)$ & 99.5 & 99.5 \\
\hline Jin, 2015 & 214 & 0.16 & 0.3000 & 177 & 0.21 & 0.2100 & + & & & -0.05 & $(-0.10 ; 0.00)$ & 0.2 & 0.2 \\
\hline Wu, 2017 & 265 & 0.28 & 0.2200 & 423 & 0.33 & 0.3500 & $\frac{1}{1}$ & — & & -0.05 & $(-0.09 ;-0.01)$ & 0.3 & 0.3 \\
\hline Fixed effect model & 1,332 & & & 1,326 & & & $\phi$ & & & -0.03 & $(-0.03 ;-0.03)$ & 100.0 & - \\
\hline Random effects model & & & & & & & $\diamond$ & 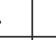 & & -0.03 & $(-0.03 ;-0.03)$ & - & 100.0 \\
\hline Heterogeneity: $R^{2}=0 \%, \tau^{2}=$ & $0, p=0$ & & & & & & $-0.1-0.05$ & 0 & $0.05 \quad 0.1$ & & & & \\
\hline
\end{tabular}

Fig. 6. Forest plot of axial length growth between the outdoor group and control group. MD, mean difference.

\section{Assessment of Publication Bias}

For all analyzed outcomes, Egger's test revealed no publication bias (Table 2). Specifically, for comparison on SER, change in SER, the number of new myopia cases and change in axial length, the $p$ values of Egger's test were $0.40,0.20,0.60$, and 0.06 respectively.

\section{Discussion}

\section{Summary of Main Results}

Based on this meta-analysis, the answer is clear that outdoor time has a positive effect on myopia control. Specifically, compared with the control group, there was an average of 0.15 (95\% CI 0.06-0.23) D benefit on refractive error. The change of refractive error of the outdoor group was slower than that of the control group by 0.17 (95\% CI $0.16-0.18)$ D. The change of axial length of the control group was faster than that of the outdoor group by -0.03 ( $95 \%$ CI -0.03 to -0.03$) \mathrm{mm}$. There were fewer new myopia cases in the outdoor group, and the pooled RR was 0.76 (95\% CI 0.67-0.87).

In summary, for myopic children, outdoor time helps slow down the speed of change in refractive error and axial length; for non-myopic children, outdoor time helps reduce the risk of developing myopia.

\section{Overall Completeness and Applicability of Evidence}

The included studies were all conducted in Singapore and China, mainly in China. Also, all subjects were Chinese students. The subjects were not representative of world population; however, they were representative of Chinese.

Besides, many factors, like study designs, sample sizes and measurement methods, could arise a large heterogeneity across studies in estimation of pooled effect size. In this meta-analysis, the outdoor time of each study dif-
Table 2. Results of Egger's test of each outcome

\begin{tabular}{lrrl}
\hline Outcomes & \multicolumn{1}{l}{$t$} & $\mathrm{df}$ & $p$ value \\
\hline SER at last follow-up & 1.37 & 1 & 0.40 \\
SER change & -1.89 & 2 & 0.20 \\
Number of new myopia cases & -0.74 & 1 & 0.60 \\
AL change & -10.88 & 1 & 0.06 \\
\hline
\end{tabular}

SER, spherical equivalent error.

fered from each other, and the measurement methods also differed from each other. Wu et al. [26] used an objective indicator, light intensity, to reflect outdoor time, while the other researchers chose to use subjective questionnaire for the measurement of outdoor time. However, there was no heterogeneity across all included studies, which further reflects that outdoor time does have a positive effect on myopia control.

\section{Quality of the Evidence}

In this review, only RCT were included, which eliminates treatment selection bias that could be influenced by participants' or researcher's desire. However, as stated in the method part, most studies performed randomization at a school-cluster level; hence, allocation concealment is not applicable, which might cause bias when assessing outcomes, since both participants and researchers know the allocation.

Overall, all studies performed random sequence generation properly and set appropriate control; therefore, the evidence was trustable.

\section{Potential Biases in the Review Process}

When performing the literature review process, in order to reduce the risk of bias, databases were searched thoroughly and papers not were screened only in English but also in 
Chinese. Two review authors independently assessed the search results for eligibility and extracted data, and therefore, the possibility that some articles were missed is low.

\section{Why Outdoor Time Does Help Myopia Prevention?}

The reason of outdoor time's positive effect on myopia control might be that the radiant intensity of sunlight peaks at a wavelength of about $550 \mathrm{~nm}$, corresponding precisely to the peak in the sensitivity of the average human observer, while indoor illumination peaks at longer wavelengths, thus most of the received light beams focus behind the retina and cause a situation similar to that of negative lenses in front of the eye, which has been proven to stimulate the globe growth and the subsequent myopia [33].

Another hypothesis states that light can induce the release of dopamine, which helps inhibit axial elongation. The evidence comes from an animal model [34], in which a translucent diffuser was placed over the eye of 1-day old White Leghorn Black Australorp cockerels and kept on a 12:12 h light/dark cycle. These birds were found to have excessively longer axial length and formed myopia. But if the diffuser was removed for $3 \mathrm{~h}$ during the light period, the axial length would not grow that much. Additionally, if the dopamine agonists were injected into the eye instead of removing the diffuser, the protective effect remained. On the contrary, the dopamine antagonists' injection prior to diffuser removal in the light could not produce the protective effect. Evidence from other studies using mice model also favored this hypothesis $[35,36]$.

\section{Agreements and Disagreements with Other Studies or}

Reviews

Our findings are similar to what Wu et al. [37] found in a comparative study, in which 571 students were recruited and 333 of them were encouraged to go outside during recess, while there was no special program for the rest of the students. It turned out that the myopia incidence of the outdoor group was lower than that of the control group (8.41 vs. $17.65 \%)$. The myopic shift of the outdoor group was also lower than that of control group ( -0.25 vs. -0.38 $\mathrm{D} /$ year). In addition, many observational studies, as mentioned in the introduction part, reported similar findings.

\section{Conclusions}

\section{Implications for Practice}

Based on available evidence, the answer is clear that outdoor time helps prevent myopia. Outdoor time can be adjusted by adding recess time during school hours and by encouraging parents and children to go outside on weekends. Besides, adding outdoor time does not cause external burden to children, parents, school, or society. Therefore, outdoor activity should be considered an effective and feasible option for myopia control.

\section{Implications for Research}

For the time being, it could only be said there is indeed a cause and effect relationship, but as for how long the outdoor time a day or a week is suggested, the answer is not clear. Studies on the dose-response relationship of outdoor time and myopia are needed. Besides, for better depiction of this dose-response relationship, the method with quantitative measurement like a light meter instead of questionnaire is suggested because a questionnaire causes large recall bias, which might be one reason why there was no statistical difference on outdoor time between the outdoor group and the control group after a 3 -year intervention program in $\mathrm{He}$ et al. [25] study.

\section{Acknowledgment}

Study design and concept (N.W., K.C.); database search (K.C., Y.W.), data extracting (K.C., Y.W.), data analysis (K.C.), manuscript writing (K.C., M.Y.), manuscript revising (K.C., N.W.).

\section{Disclosure Statement}

The authors declare no conflicts of interest.

\section{Appendix 1}

Search Strategy for Pubmed

The search strategy was ("myopia" [MeSH Terms] OR "myopia" [All Fields]) AND ("random allocation" [MeSH Terms] OR ("random" [All Fields] AND "allocation" [All Fields]) OR "random allocation" [All Fields] OR "randomized" [All Fields] OR "intervention" [All Fields] OR ("prevention and control" [Subheading] OR ("prevention" [All Fields] AND "control" [All Fields]) OR "prevention and control" [All Fields] OR "control" [All Fields] OR "control groups" [MeSH Terms] OR ("control” [All Fields] AND "groups" [All Fields]) OR "control groups" [All Fields])) AND outdoor [All Fields].

\section{Appendix 2}

Search Strategy for Other Databases

The search strategy was "myopia and (randomization or random allocation or randomized) and (prevention or control or intervention)." 


\section{References}

1 Pan CW, Dirani M, Cheng CY, Wong TY, Saw SM. The age-specific prevalence of myopia in Asia: a meta-analysis. Optom Vis Sci. 2015 Mar;92(3):258-66.

2 Dolgin E. The myopia boom. Nature. 2015 Mar;519(7543):276-8.

3 Lin Z, Gao TY, Vasudevan B, Ciuffreda KJ, Liang YB, Jhanji V, et al. Near work, outdoor activity, and myopia in children in rural China: the Handan offspring myopia study. BMC Ophthalmol. 2017 Nov; 17(1):203.

4 Yang M, Luensmann D, Fonn D, Woods J, Jones D, Gordon K, et al. Myopia prevalence in Canadian school children: a pilot study. Eye (Lond). 2018 Jun;32(6):1042-7.

5 Theophanous C, Modjtahedi BS, Batech M, Marlin DS, Luong TQ, Fong DS. Myopia prevalence and risk factors in children. Clin Ophthalmol. 2018 Aug;12:1581-7.

6 Choi JA, Han K, Park YM, et al. Low Serum 25-Hydroxyvitamin D Is Associated with Myopia in Korean Adolescents. Invest Ophthalmol Vis Sci. 2014 Apr 3;55(4):2041-7.

7 Fang Y, Yokoi T, Nagaoka N, Shinohara K, Onishi Y, Ishida T, et al. Progression of Myopic Maculopathy during 18-Year Follow-up. Ophthalmology. 2018 Jun;125(6):863-77.

8 Wei CC, Kung YJ, Chen CS, Chang CY, Lin CJ, Tien PT, et al. Allergic Conjunctivitis-induced Retinal Inflammation Promotes Myopia Progression. EBioMedicine. 2018 Feb;28:274-86.

9 Low W, Dirani M, Gazzard G, Chan YH, Zhou HJ, Selvaraj P, et al. Family history, near work, outdoor activity, and myopia in Singapore Chinese preschool children. Br J Ophthalmol. 2010 Aug;94(8): 1012-6.

10 Lu B, Congdon N, Liu X, Choi K, Lam DS, Zhang $\mathrm{M}$, et al. Associations between near work, outdoor activity, and myopia among adolescent students in rural China: the Xichang Pediatric Refractive Error Study report no. 2. Arch Ophthalmol. 2009 Jun; 127(6):769-75.

11 Ip JM, Saw SM, Rose KA, Morgan IG, Kifley A, Wang JJ, et al. Role of near work in myopia: findings in a sample of Australian school children. Invest Ophthalmol Vis Sci. 2008 Jul; 49(7):2903-10.

12 Saw SM, Shankar A, Tan SB, Taylor H, Tan DT, Stone RA, et al. A cohort study of incident myopia in Singaporean children. Invest Ophthalmol Vis Sci. 2006 May;47(5):1839-44.

13 Li SM, Li H, Li SY, Liu LR, Kang MT, Wang YP, et al.; Anyang Childhood Eye Study Group. Time Outdoors and Myopia Progression Over 2 Years in Chinese Children: The Anyang Childhood Eye Study. Invest Ophthalmol Vis Sci. 2015 Jul;56(8):4734-40.
14 Chua SY, Ikram MK, Tan CS, Lee YS, Ni Y, Shirong C, et al.; Growing Up in Singapore Towards Healthy Outcomes Study Group. Relative Contribution of Risk Factors for Early-Onset Myopia in Young Asian Children. Invest Ophthalmol Vis Sci. 2015 Dec;56(13): 8101-7.

15 McKnight CM, Sherwin JC, Yazar S, Forward H, Tan AX, Hewitt AW, et al. Myopia in young adults is inversely related to an objective marker of ocular sun exposure: the Western Australian Raine cohort study. Am J Ophthalmol. 2014 Nov;158(5):1079-85.

16 Deng L, Gwiazda J, Thorn F. Children's refractions and visual activities in the school year and summer. Optom Vis Sci. 2010 Jun; 87(6):406-13.

17 Khader YS, Batayha WQ, Abdul-Aziz SM, AlShiekh-Khalil MI. Prevalence and risk indicators of myopia among schoolchildren in Amman, Jordan. East Mediterr Health J. 2006 May-Jul;12(3-4):434-9.

18 Mutti DO, Mitchell GL, Moeschberger ML, Jones LA, Zadnik K. Parental myopia, near work, school achievement, and children's refractive error. Invest Ophthalmol Vis Sci. 2002 Dec;43(12):3633-40

19 Saxena R, Vashist P, Tandon R, Pandey RM, Bhardawaj A, Gupta V, et al. Incidence and progression of myopia and associated factors in urban school children in Delhi: The North India Myopia Study (NIM Study). PLoS One. 2017 Dec;12(12):e0189774.

20 Sun JT, An M, Yan XB, Li GH, Wang DB. Prevalence and Related Factors for Myopia in School-Aged Children in Qingdao. J Ophthalmol. 2018 Jan;2018:9781987.

21 Guo Y, Liu LJ, Tang P, Lv YY, Feng Y, Xu L, et al. Outdoor activity and myopia progression in 4-year follow-up of Chinese primary school children: The Beijing Children Eye Study. PLoS One. 2017 Apr;12(4):e0175921.

22 Hsu CC, Huang N, Lin PY, Tsai DC, Tsai CY, Woung LC, et al. Prevalence and risk factors for myopia in second-grade primary school children in Taipei: A population-based study. J Chin Med Assoc. 2016 Nov;79(11): 625-32.

23 Read SA, Collins MJ, Vincent SJ. Light exposure and physical activity in myopic and emmetropic children. Optom Vis Sci. 2014 Mar; 91(3):330-41.

24 Jin JX, Hua WJ, Jiang X, Wu XY, Yang JW, Gao GP, et al. Effect of outdoor activity on myopia onset and progression in school-aged children in northeast China: the Sujiatun Eye Care Study. BMC Ophthalmol. 2015 Jul;15:73.

25 He M, Xiang F, Zeng Y, Mai J, Chen Q, Zhang $J$, et al. Effect of Time Spent Outdoors at
School on the Development of Myopia Among Children in China: A Randomized Clinical Trial. JAMA. 2015 Sep;314(11): 1142-8.

26 Wu PC, Chen CT, Lin KK, Sun CC, Kuo CN, Huang HM, et al. Myopia Prevention and Outdoor Light Intensity in a School-Based Cluster Randomized Trial. Ophthalmology. 2018 Aug;125(8):1239-50.

27 Czepita M, Kuprjanowicz L, Safranow K, Mojsa A, Majdanik E, Ustianowska M, et al. The role of outdoor activity in the development of myopia in schoolchildren. Pomeranian J Life Sci. 2016;62(4):30-2.

28 http://training.cochrane.org/handbook[EB/ OL].

29 Borenstein M, Hedges LV, Higgins JP, Rothstein HR. A basic introduction to fixed-effect and random-effects models for meta-analysis. Res Synth Methods. 2010 Apr;1(2):97111 .

30 Egger M, Davey Smith G, Schneider M, Minder C. Bias in meta-analysis detected by a simple, graphical test. BMJ. 1997 Sep;315(7109): 629-34.

31 YiJH, Li RR. [Influence of near-work and outdoor activities on myopia progression in school children]. Zhongguo Dang Dai Er Ke Za Zhi. 2011 Jan;13(1):32-5.

32 Ngo CS, Pan CW, Finkelstein EA, Lee CF, Wong IB, Ong J, et al. A cluster randomised controlled trial evaluating an incentive-based outdoor physical activity programme to increase outdoor time and prevent myopia in children. Ophthalmic Physiol Opt. 2014 May; 34(3):362-8.

33 Schmid KL, Wildsoet CF. Effects on the compensatory responses to positive and negative lenses of intermittent lens wear and ciliary nerve section in chicks. Vision Res. 1996 Apr; 36(7):1023-36.

34 McCarthy CS, Megaw P, Devadas M, Morgan IG. Dopaminergic agents affect the ability of brief periods of normal vision to prevent form-deprivation myopia. Exp Eye Res. 2007 Jan;84(1):100-7.

35 Ashby R. Animal Studies and the Mechanism of Myopia-Protection by Light?. Optom Vis Sci. 2016 Sep;93(9):1052-4.

36 Morgan IG, Ashby RS. Bright Light Blocks the Development of Form Deprivation Myopia in Mice, Acting on D1 Dopamine Receptors. Invest Ophthalmol Vis Sci. 2017 Apr;58(4): 2317.

37 Wu PC, Tsai CL, Wu HL, Yang YH, Kuo HK. Outdoor activity during class recess reduces myopia onset and progression in school children. Ophthalmology. 2013 May; 120(5): 1080-5. 